Personalidade Acadêmica Homenageada:

Augustus B. Cochran III (Agnes Scott College)

\title{
A ERA VARGAS E UM BREVE ENSAIO HISTÓRICO DE SUAS FASES
}

\section{THE VARGAS ERA AND A BRIEF HISTORICAL TEST OF ITS PHASES}

\begin{abstract}
PRISCILA LUCIENE SANTOS DE LIMA
Doutoranda em Direito Político e Econômico pela Universidade Presbiteriana Mackenzie - UPM; Mestre em Direito Empresarial e Cidadania do Centro Universitário Curitiba - UNICURITIBA; Especialista em Direito do Trabalho e Processo do Trabalho pela Pontifícia Universidade Católica do Paraná - PUCPR; Bacharel em Direito pela Universidade Tuiuti do Paraná - UTP. Professora e Advogada. Email: pritysantoslima@hotmail.com
\end{abstract}

\section{LOURENÇO DE MIRANDA FREIRE NETO}

Doutorando em Direito Político e Econômico pela Universidade Presbiteriana Mackenzie - UPM; Mestre em Direito pela Universidade Católica de Pernambuco. Bacharel em Direito pela Universidade Federal da Paraíba. Professor efetivo na Universidade Federal da Paraíba. Email: lourencomiranda@gmail.com.

\section{RESUMO}

O presente artigo visa explanar sobre a Revolução de 30, movimento militar que levou Getúlio Vargas ao poder. Aprimorar os conhecimentos sobre a Era Vargas e suas fases, compreendida entre 1930 e 1945. Perpassando pela contextualização histórica das três fases, Governo Provisório, Governo Constitucional e Estado Novo, 
Personalidade Acadêmica Homenageada:

Augustus B. Cochran III (Agnes Scott College)

bem como suas definições e características. Desta feita, busca-se identificar de que forma a Era Vargas contribuiu para a história e formação política do Brasil. Realizase na presente pesquisa, uma abordagem qualitativa, a partir do estudo bibliográfico.

PALAVRAS-CHAVES: Revolução; Governo Provisório; Governo Constitucional; Estado Novo; Era Vargas.

\begin{abstract}
This article intends to explain the Revolution of 30 , the military movement that brought Getúlio Vargas to power. To improve knowledge about the Vargas Era and its phases, between 1930 and 1945. Through the historical contextualization of the three phases, Provisional Government, Constitutional Government and New State, as well as its definitions and characteristics, that is, it seeks to identify Vargas Era contributed to the history and political formation of Brazil. A qualitative approach is carried out in the present research, based on the bibliographic study.
\end{abstract}

KEYWORDS: Revolution; Provisional Government; Constitutional Government; New state; Vargas Era.

\title{
INTRODUÇÃO
}

A Revolução de 1930, foi um movimento liderado por representantes de Minas Gerais, Paraíba e Rio Grande do Sul contra a política oligárquica que comandava o Brasil na época.

Esse movimento destituiu Washington Luís do Poder e impediu a posse do presidente eleito nas eleições de 1930, Júlio Prestes. Com esses acontecimentos, 
Personalidade Acadêmica Homenageada:

Augustus B. Cochran III (Agnes Scott College)

chegou ao fim a República Velha e instaurou-se no Brasil, a Era Vargas, que começou pelo Governo Provisório.

O Brasil era controlado pela política do café com leite, onde paulistas e mineiros revezavam a presidência do país. Em 1930 teria eleição e o atual presidente da época, Washington Luís, deveria indicar ao poder um representante mineiro, pois era a vez dos mineiros governarem o Brasil. Porém, isso não aconteceu, Washington Luís indicou Júlio Prestes, um paulista, quebrando assim, aquele revezamento que deveria ser feito. Essa quebra de acordo fez com que os mineiros, naquele exato momento, rompessem a amizade com os paulistas. Insatisfeitos com a situação e desejando responder essa atitude à altura, os mineiros procuraram apoio e se aliaram aos paraibanos e gaúchos.

Essa união de Minas Gerais, com a Paraíba e o Rio Grande do Sul deu origem a aliança liberal, em 1929. O candidato a Presidência que os mineiros tinham era Antônio Carlos, mas o acordo feito com a Paraíba e o Rio Grande do Sul rendeu a esses Estados a possibilidade de escolherem seus representantes.

Então, ficou assim, o Rio Grande do Sul apresentava Getúlio Vargas como candidato a Presidente, e a Paraíba apresentava João Pessoa como seu candidato a Vice-presidente. De outro lado, Júlio Prestes e seu vice Vital Soares, pronto, estavam formadas as uniões que disputariam as eleições de 1930.

Júlio Prestes e seu vice saíram vitoriosos na eleição, foram acusados de fraudar os votos, mas nada aconteceu. Em 26 de julho, o vice de Getúlio Vargas foi assassinado por opositores de seu Estado. Mas, o culpado pela morte de João Pessoa foi o governo de Washington. Logo em seguida, a aliança liberal começava a convencer os militares a derrubar Washington Luís e colocar em seu lugar Getúlio Vargas.

Aos poucos, foram conseguindo apoio de mais militares e esses foram os responsáveis pela organização de forças militares que ajudariam Getúlio a chegar 
Personalidade Acadêmica Homenageada:

Augustus B. Cochran III (Agnes Scott College)

até o poder. Em 24 de outubro de 1930, as forças armadas depuseram Washington Luís, e uma junta provisória militar ficou no controle do país.

Getúlio Vargas, na companhia de militares e apoiadores, seguiu até o Rio de Janeiro, onde assumiria a presidência do Brasil em 3 de novembro de 1930.

A chegada de Getúlio ao Poder marca o fim da República Velha como política do café com leite e o início do governo provisório, a primeira das três partes da Era Vargas.

\section{PRIMEIRA FASE - 1930 A 1934 - GOVERNO PROVISÓRIO}

Diz-se Governo Provisório porque Getúlio Vargas chega ao Poder através da Revolução de 1930, assumindo a presidência de forma interina, até que fossem convocadas novas eleições presidenciais.

Durante o referido período, Vargas vai governar através de Decretos-leis, uma vez que o Congresso estava fechado, e que não havia uma Constituição. Pois a Constituição da República Velha, ou seja, a Constituição de 1891, foi extinta quando Vargas chega ao Poder.

Além disso, ele vai nomear para cada Estado da federação, interventores de sua máxima confiança. Normalmente, esses cargos foram ocupados por tenentes que o apoiaram durante a Revolução de 1930, com exceção do Estado de Minas Gerais, que não recebeu um interventor federal nomeado.

Nesse sentido, observa Bercovici:

O tenentismo não foi um movimento homogêneo, mas é possível determinar pontos que os uniam, como a crença de que os tenentes seriam os responsáveis pela defesa das instituições republicanas e a pregação da necessidade de eleições honestas e do voto secreto (BERCOVICI, 2008, p. 376). 
Personalidade Acadêmica Homenageada:

Augustus B. Cochran III (Agnes Scott College)

Outra característica do período é um atrelamento dos sindicatos ao Governo. Significa dizer que, os sindicatos para serem validados os seus registros, precisavam estar atrelados ao Ministério do Trabalho, ao recém-criado, Ministério do Trabalho, Indústria e Comércio, que ficou a cargo de Lindolfo Collor.

Destacando aqui, que a questão social durante a República Velha era considerada um caso de polícia, segundo Washington Luís. Ou seja, as manifestações operárias eram violentamente reprimidas durante a República Velha, inclusive com os burgos, com banimentos de muitos imigrantes.

Havia ainda, a vigência da Lei Adolpho Gordo, que permitia a expulsão de imigrantes que promovessem arruaças, esse termo era utilizado para greves, piquetes, passeatas, manifestações grevistas ocorridas no Brasil.

Portanto, durante a República Velha a questão social era encarada como caso de polícia. Nessa fase, esse discurso teve uma sensível mudança, pois a questão social durante a Era Vargas passa a ser considerada um caso de política nacional. Muda-se, de caso de polícia para caso de política.

Ainda durante o Governo Provisório, nós temos a criação das primeiras leis trabalhistas no Brasil, por exemplo: jornada de trabalho de 8 horas diárias, a criação do salário mínimo, da aposentadoria, do direito de férias remuneradas, da estabilidade no emprego.

Esses direitos são fruto de muita luta, de uma histórica luta do movimento operário durante o século $\mathrm{XX}$, que foi colocado em prática durante o Governo Vargas, com a implementação das primeiras leis trabalhistas no Brasil.

Também ocorre nessa fase, a Revolução Constitucionalista de São Paulo em 1932. Essa Revolução foi uma reação da Oligarquia cafeeira paulista insatisfeita com a exclusão do Poder. São Paulo vai pegar em armas para tentar derrubar o presidente Getúlio Vargas do poder. Esse movimento vai contar com o apoio da classe média urbana que estava insatisfeita com o autoritarismo varguista e principalmente, com a indicação de um interventor federal não paulista para 
Personalidade Acadêmica Homenageada:

Augustus B. Cochran III (Agnes Scott College)

governar o Estado de São Paulo. Forma-se então o Movimento M.M.D.C., os paulistas vão se alistar para enfrentar o Governo Federal.

A sigla M.M.D.C., foi retirada de estudantes mortos em manifestações contra o Governo Federal, cujos sobrenomes eram Martins, Miragaia, Dráusio e Camargo.

O objetivo dessa Revolução era forçar o presidente Getúlio Vargas a convocar eleições para a formação de uma Assembleia Nacional Constituinte. Portanto, os paulistas desejavam a implementação de uma nova Constituição no Brasil.

Essa Guerra vai durar alguns meses e termina com derrota militar dos paulistas. Getúlio Vargas vence nas armas, mas do ponto de vista político pode-se dizer que São Paulo sai vitorioso, pois Vargas convoca eleições para a formação da Assembleia Nacional Constituinte em 1933, para que seja elaborada a nova Constituição Federal, sendo o auge, como demonstra José Murilo de Carvalho:

\begin{abstract}
À medida que se tornava clara a vitória dos Aliados, intensificava-se a preparação para a democratização e o apelo aos operários. A imagem de Vargas como o "pai dos pobres", o amigo dos operários, foi sendo sistematicamente construída. O movimento chegou ao auge com a proposta de uma Assembleia Constituinte com Vargas, apoiada até mesmo pelo Partido Comunista do Brasil. Essa guinada, foi a causa imediata do divórcio entre Vargas e as Forças Armadas. Estas, ou melhor a facção que as dominava, já então tomadas pelo anticomunismo e pela pretensão de guiar o Estado, não aceitaram a busca de novo ator político que lhe era política e ideologicamente antagônico. (CARVALHO, 1999)
\end{abstract}

Com um detalhe interessante, é a primeira eleição no Brasil que vai contar com o voto feminino. As mulheres conseguem direito ao voto no Brasil com a Reforma do Código Eleitoral, ocorrida em 1932. Ou seja, o movimento sufragista feminino alcançou a sua meta de conseguir participar ativamente da política nacional. 
Personalidade Acadêmica Homenageada:

Augustus B. Cochran III (Agnes Scott College)

\section{SEGUNDA FASE - 1934 A 1937 - GOVERNO CONSTITUCIONAL}

Nessa fase então, temos a criação da Constituição de 1934, que apresentava como características o voto secreto, obrigatório e direto. Portanto, o voto deixa de ser aberto, e passa a ser secreto.

Além disso, Getúlio Vargas cria a Justiça Eleitoral e dá direito ao voto às mulheres. Entretanto, cabe ressaltar que os analfabetos, maioria esmagadora da nação, permaneciam excluídos da participação política.

Uma outra característica da Constituição de 1934 foi o corporativismo, ou seja, o Estado se apresenta como mediador da luta de classes. A histórica disputa entre capital representado pelos empresários e o trabalho representado pelos operários, vai ser evitada pelo Estado com a implementação do corporativismo. Diminuindo assim o atrito entre a burguesia industrial e os operários.

Segundo Bercovici, "o que acontece em 1934, fundamentalmente, é a constitucionalização das medidas tomadas pelo Governo Provisório de Getúlio Vargas”. (BERCOVICI, 2005, p. 17). Sendo considerada a primeira Constituição Econômica no Brasil.

Ocorre ainda, a confirmação das leis trabalhistas, os primeiros direitos trabalhistas implementados ainda durante o Governo Provisório são referendados durante a Constituição de 1934.

Neste sentido, Amaral registra que:

O mundo, a realidade objetiva, a crise internacional e a crise nacional, a polarização ideológica, o fascismo e o comunismo em ascensão, a emergência da socialdemocracia européia, a luta de classes no proscênio. Hitler e Stalin no poder. Tudo isso faria a Constituição de 1934 essencialmente diversa de sua antecessora, e seu caráter mais distintivo será a consagração de temas como a Nova Ordem econômica e as preocupações com questão social (que deixava de ser 'caso de polícia'). (AMARAL, 2004). 
Personalidade Acadêmica Homenageada:

Augustus B. Cochran III (Agnes Scott College)

Mais uma novidade é o estabelecimento do mandato presidencial de 4 anos. Ou seja, Getúlio Vargas ganha mais 4 anos no poder, pois o Congresso nacional, a Assembleia Nacional Constituinte que se reuniu para elaborar a Constituição de 1934, concedeu mais 4 anos de mandato para Vargas. Portanto, Getúlio Vargas é o primeiro presidente eleito indiretamente.

Além disso, mais uma característica seria a intervenção do Estado na exploração de minérios no Brasil.

Durante o Governo Constitucional de Vargas, nós temos a formação de duas correntes políticas antagônicas, influenciadas pela conjuntura internacional. Pois vejam bem, na Europa nós tínhamos uma grande polarização ideológica com o estabelecimento de regimes totalitários em vários países daquele continente. Temos a ascensão do nazifascismo, o fascismo de Benito Mussolini na Itália chegou ao poder em 1922, e o nazismo de Adolf Hitler na Alemanha, que se instala no poder em 1933. Ao mesmo tempo, nós temos a consolidação do socialismo, o governo de Joseph Stalin na União Soviética.

Todas essas transformações políticas, toda essa polarização ideológica, extrema direita, extrema esquerda, vão ressoar no Brasil. Essas ideias, a defesa do comunismo e a defesa do nazifascismo chegam até aqui e contribuem para a formação de duas agremiações antagônicas. Uma de tendência fascista e outra de tendência comunista, temos então a formação da AIB, ou seja, Ação Integralista Brasileira.

A AIB é um grupo de tendência fascista, que tinha como principal líder Plínio Salgado, a qual condenava o capitalismo financeiro internacional associado aos judeus, mas não condenava a propriedade privada. A AIB defendia a implantação do totalitarismo no Brasil, ou seja, um Governo autocrático ditatorial. Defendia o unipartidarismo, ou seja, a existência de um único partido político, no caso o partido de sustentação ao Governo, e a implantação de um Estado Centralizado e forte no País. 
Personalidade Acadêmica Homenageada:

Augustus B. Cochran III (Agnes Scott College)

O lema da AIB era "Deus, Pátria e Família", usavam uniforme verde com a letra grega o "sigma" como símbolo, e a saudação característica desse grupo era em tupi "anauê".

Os chamados integralistas tinham apoio de setores conservadores da Igreja Católica, porque o grupo contrário era um grupo de comunistas ateus. Também tinham o apoio da classe média alta de empresários capitalistas e de imigrantes descendentes de italianos e alemães, principalmente nos Estados do sul do Brasil.

O outro grupo político que se forma nesse contexto histórico durante o Governo Constitucional de Getúlio Vargas, foi a ANL ou Aliança Nacional Libertadora. Era uma aliança de esquerda, que reunia comunistas, socialistas, democratas e simpatizantes de esquerda em geral.

O principal líder da ANL era Luís Carlos Prestes, o famoso cavaleiro da esperança, o líder da Coluna Prestes durante da década de 20, Luís Carlos Prestes depois de passar um longo período no exílio, estava na União Soviética, retorna ao Brasil e vai se juntar à Aliança Nacional Libertadora.

Essa aliança defendia o não pagamento da dívida externa brasileira, defendia ainda a reforma agrária e o respeito as liberdades individuais, como o direito de greve, imprensa livre. Defendia também a nacionalização de empresas estrangeiras e a instalação de um Governo popular no Brasil.

Porém, Getúlio Vargas colocou a Aliança Nacional Libertadora na ilegalidade em julho de 1935. E em novembro desse mesmo ano, ocorreu um movimento denominado posteriormente de Intentona Comunista, que foi uma tentativa frustrada de golpe por membros da ANL, que tentam derrubar o governo de Getúlio Vargas. Entretanto, essa manifestação, mal organizada, acabou fracassando rapidamente, e os principais líderes, incluindo Luís Carlos Prestes e sua companheira alemã Olga Benário foram presos.

Em 1937, Getúlio Vargas vai divulgar para a Nação a existência de um suposto plano comunista para tomar o poder do Brasil. Um fictício plano de 
Personalidade Acadêmica Homenageada:

Augustus B. Cochran III (Agnes Scott College)

dominação comunista do Brasil, denominado de Plano Cowen. Vargas divulga através do rádio essa suposta ameaça de implantação do socialismo no Brasil, que vai ser usado como uma justificativa para continuar no poder e implantar um governo ditatorial em 10 de novembro de 1937.

\section{TERCEIRA FASE - 1937 A 1945 - ESTADO NOVO}

Em 10 de novembro de 1937, Getúlio Vargas implantou o Estado Novo no Brasil, inaugurando a terceira e última fase da Era Vargas. Um período ditatorial em que houve muita repressão, em que havia censura aos meios de comunicação, houve prisões, não havia liberdade de imprensa.

Segundo Bonavides:

Com o advento do Estado Novo, prosseguiria Vargas a obra social de sua primeira ditadura. O Estado Novo foi, no entanto, um Estado social despolitizado na aparência; uma criação do arbítrio de Vargas em termos tão unipessoais que o ditador governou discricionariamente sem Congresso, sem partidos políticos, sem eleições, sem nenhuma base de representatividade formal. Os instrumentos de força, como a censura, a lei de segurança nacional, os órgãos de propaganda concentrada, o culto dirigido da personalidade, o tribunal de exceção, os cárceres políticos consubstanciavam os elementos de sustentação da ditadura. (BONAVIDES, 2006, p. 81)

Enfim, uma ditadura comandada pelo presidente Getúlio Vargas. O Congresso foi fechado e as eleições que seriam realizadas no ano seguinte foram suspensas. Assim, Getúlio Vargas permanece no poder, desta feita, como ditador.

Nessa fase, Vargas já outorga uma nova Constituição, a CF de 1937, apelidada de Constituição Polaca, por ser de tendência fascista, extremamente conservadora. 
Personalidade Acadêmica Homenageada:

Augustus B. Cochran III (Agnes Scott College)

Nós temos a instalação de um Estado de emergência permanente, onde plenos poderes são dados ao presidente da república e também a polícia do Estado Novo.

Uma vez fechado o Congresso Nacional, foram editados decretos-lei. Temos também a proibição das greves operárias, a censura permanente aos meios de comunicação, através da atuação do DIP, Departamento de Imprensa e Propaganda. Um órgão criado pela estrutura burocrática do Estado Novo.

Temos também, a prisão de vários opositores ao regime político, dentre eles, Graciliano Ramos, o qual escreve na prisão Memórias do Cárcere.

Esse período é marcado pelo apoio das forças armadas, o exército, a marinha e a aeronáutica vão se posicionar a favor do Estado Novo. E, pela ausência de qualquer partido no país, quando a AIB (Ação Integralista Brasileira) foi fechada a mando de Getúlio Vargas.

Em 1938, ocorre a Intentona Integralista, que foi um fracassado golpe desfechado pela AIB contra Getúlio Vargas. Os líderes do movimento acabaram presos e o principal líder da AIB, Plínio Salgado, foi exilado para Portugal.

$\mathrm{Na}$ política internacional, nós temos um comportamento pragmático do Estado Novo, porque o governo vai explorar as rivalidades internacionais para obter vantagens para o Brasil. Portanto, durante o Estado Novo, Vargas e a sua elite burocrática adotaram um comportamento pendular, ora atendendo aos países totalitários como Itália e Alemanha, ora atendendo aos Estados Unidos, fazendo uma espécie de barganha para saber quem poderia contribuir para o processo de consolidação da industrialização do Brasil com apoio estatal. Ou seja, esperava conseguir vantagens para o seu projeto de industrialização, com o destaque para a implantação das chamadas indústrias de base que vão acontecer no contexto histórico da Segunda Guerra mundial, quando o Brasil implanta a Companhia Siderúrgica Nacional em 1942, com o apoio do capital norte-americano. Em troca, o Brasil participa da Segunda Guerra mundial junto aos aliados. 
Personalidade Acadêmica Homenageada:

Augustus B. Cochran III (Agnes Scott College)

Em 1942, vários navios mercantes brasileiros foram afundados por submarinos alemães, o que provoca um grande clamor populacional, a imprensa exige uma tomada de decisão, uma postura mais enérgica do presidente Vargas, que acaba decretando guerra contra os países do eixo, ou seja, Alemanha, Itália e Japão.

No Brasil, as colônias ligadas a esses três países, acabam sofrendo uma espécie de perseguição. Várias entidades de imigrantes acabam sendo fechadas, inclusive. Um destaque interessante, são dois grandes clubes de futebol existentes na década de 40 que tiveram que alterar sua razão social, mudar o nome dessas agremiações para que elas não fossem fechadas. Justamente, é o Palestra Itália de São Paulo que passa a adotar o nome de Palmeiras e o Palestra Itália de Belo Horizonte, que passa a adotar no nome de Cruzeiro, porque ambos tinham referência aos inimigos do Brasil, aos quais havia sido declarado Guerra.

Em $1^{\circ}$ de maio de 1943, ocorre a edição da Consolidação das Leis Trabalhistas, no Estádio de São Januário, Estádio do Clube de Regatas Vasco da Gama, Getúlio Vargas decreta a CLT. Legislação que consta os direitos trabalhistas, à partir de então, passamos a ter uma relação corporativista entre o Estado e os trabalhadores.

No ano seguinte, em 1944, Getúlio Vargas envia para os campos de batalha na Itália, a Força Expedicionária Brasileira - FEB, com aproximadamente 25 mil homens. E a luta contra o nazifascismo estabelece uma contradição interna: ditadura lutando ao lado das "forças pró-democracia". Esse evento é conhecido como o grande paradoxo do Estado Novo.

Perceba, o Brasil era uma ditadura, vivia um clima de ausência de democracia. Entretanto, na Segunda Guerra mundial, o Brasil lutava junto das forças democráticas contra os regimes autoritários. Criou uma situação paradoxal que vai contribuir para o fim do Estado Novo logo após o final da Segunda Guerra mundial. 
Personalidade Acadêmica Homenageada:

Augustus B. Cochran III (Agnes Scott College)

Portanto, nesse contexto, diversos setores sociais começam a pedir a democracia interna, o restabelecimento da democracia no Brasil. Entre esses grupos destacam-se a UNE - União Nacional dos Estudantes (criada em 1937), os meios de comunicação, rádio, jornal, que apesar da censura efetuada pelo DIP, começam a pressionar. E também temos destaque para o movimento dos mineiros, que contou inclusive com a participação do escritor Carlos Drummond de Andrade.

Diante do contexto apresentado, Getúlio Vargas convoca eleições para 1945, acaba com a censura à imprensa e à anistia aos presos políticos. Como a oposição ao Estado Novo crescia, essas foram algumas tentativas de mudar o jogo. A esperança do Governo Vargas era de que ele pudesse concorrer novamente as eleições presidenciais de 1945.

Já no final do Estado Novo, Vargas cria dois importantes partidos políticos nacionais: o PTB - Partido Trabalhista Brasileiro, baseado no apoio do trabalhismo, no apoio dos operários, ficando conhecido assim como o pai dos pobres no Brasil; e o PSD - Partido Social Democrático, ligado a setores empresariais. Assim, existia a tentativa de agradar tanto trabalhadores quanto elementos da elite nacional.

Após a criação dos partidos, surgiu o movimento queremista, que era de cunho popular, apoiado discretamente por Vargas para tentar a sua continuidade no poder. Outra tentativa também, é tentar se aliar aos comunistas, pois O PCB Partido Comunista Brasileiro, que estava na ilegalidade durante o Estado Novo, volta e com isso Vargas tenta se aproximar de suas lideranças.

Outra iniciativa de Getúlio Vargas é propor uma "Lei Anti-Truste", que desagrada os interesses capitalistas dos Estados Unidos. Com isso, em 1945, Vargas é afastado do poder pelo exército (influenciado pelos EUA), que temia uma nova tentativa golpista do presidente. Sendo assim, Getúlio Vargas retorna para São Borja e é eleito posteriormente, senador por dois Estados ao mesmo tempo, São Paulo e Rio Grande do Sul. 
Personalidade Acadêmica Homenageada:

Augustus B. Cochran III (Agnes Scott College)

José Linhares, que era presidente do Supremo Tribunal Federal, assume a Presidência da República até que as eleições tivessem transcorrido e o novo presidente assumisse. Já que durante o Estado Novo não havia a figura do vicepresidente, ou seja, Getúlio Vargas governava sozinho, e ainda nesse sentido, o Congresso nacional estava fechado. Sendo assim, na ausência do presidente da Câmara dos Deputados e do presidente do Senado, evidentemente, quem assume a presidência é o presidente do STF.

\section{CONCLUSÃO}

Podemos concluir que, diversas foram as características de grande importância durante o Governo Vargas.

Getúlio Vargas inaugurou uma política denominada populismo, que foi um tipo de governo que possuiu as seguintes características: autoritarismo, estatismo, corporativismo, concessões parciais a camada mais pobre da população, visando obter seu apoio.

O Estado se apresenta como mediador dos conflitos sociais, é o chamado corporativismo, ou seja, o Estado se apresenta como interventor entre a luta de classes, entre capital e trabalho.

Temos também, como característica do governo Vargas, o nacionalismo econômico, com a criação de empresas estatais e a construção de grandes obras públicas, como a CSN - Companhia Siderúrgica Nacional e da Companhia Vale do Rio Doce, duas importantes estatais responsáveis pela industrialização de base no Brasil.

Relevante, falarmos na Intervenção do Estado na economia, bem como no controle dos trabalhadores com criação de leis, haja vista a decretação da 
Personalidade Acadêmica Homenageada:

Augustus B. Cochran III (Agnes Scott College)

Consolidação das Leis Trabalhistas e o atrelamento dos Sindicatos ao Ministério do Trabalho, Indústria e Comércio.

Além disso, temos a utilização intensa de propaganda governamental e censura, com a criação da DIP - Departamento de Imprensa e Propaganda, que tinha a intenção de criar uma imagem positiva de Getúlio Vargas para a população, principalmente através do rádio, que era o meio de comunicação de massa. Destacando a criação da "Hora do Brasil", criado durante o Estado Novo, que hoje chama-se "Voz do Brasil". O que resultou a imagem do "pai dos pobres", ou seja, a aproximação com as camadas trabalhadoras do Brasil, o conhecido trabalhismo.

Tivemos também, o incentivo ao mercado interno e uma política de valorização do café, com a recuperação do preço do produto mediante a queima dos estoques excedentes. E, o incentivo a indústria nacional, principalmente a Indústria de base, durante a Segunda Guerra Mundial, quando foi criada a Companhia Siderúrgica Nacional e a nacionalização das refinarias de Petróleo.

Enfim, além de ilustrar um pouco da história compreendida entre os anos de 1930 a 145, período conhecido como "A Era Vargas", bem como resgatar as inúmeras heranças deixadas por Getúlio Vargas, que continuam a influenciar e ecoar até os dias atuais.

\section{REFERÊNCIAS}

BRASIL. Constituição da República Federativa do Brasil de 5 de Outubro de 1988. Disponível em: <http://www.planalto.gov.br/ccivil_03/constituicao/constituicaocompilado.htm. Acesso em 22/10/2018.

Constituição Federal de 1934. Disponível em: < http://www.planalto.gov.br/ccivil_03/constituicao/constituicao34.htm>. Acesso em 22/10/2018. 
Personalidade Acadêmica Homenageada:

Augustus B. Cochran III (Agnes Scott College)

. Constituição dos Estados Unidos do Brasil de 1937. Disponível em: < http://www.planalto.gov.br/ccivil_03/constituicao/constituicao37.htm. Acesso em 22/10/2018.

Decreto-Lei $\mathrm{n}^{\circ}$ 869, de 18 de Novembro de 1938. Disponível em: $<$ http://legis.senado.gov.br/legislacao/ListaNormas.action?numero=869\&tipo_norma= DEL\&data $=19381118 \&$ link=s $>$. Acesso em 22/10/2018.

. Decreto-Lei n. 7.666, de 22 de junho de 1945. Disponível em: < http://www.planalto.gov.br/ccivil_03/decreto-lei/Del7666.htm>. Acesso em 22/10/2018.

<http://www.planalto.gov.br/ccivil 03/leis/1950-1969/L4137.htm.
. Lei $\mathrm{n}^{\circ}$ 4.137, de 10 de Setembro de 1962. Disponível em:
Acesso 22/10/2018.

. Decreto n. 99.244, de 10 de maio de 1990. Disponível em: < http://www.planalto.gov.br/ccivil_03/decreto/D99244.htm>. Acesso em 22/10/2018.

Lei 8.158, de 08 de Janeiro de 1991. Disponível em: <http://www.planalto.gov.br/ccivil_03/leis/L8158.htm>. Acesso em 22/10/2018.

Lei 8.884, de 11 de Junho de 1994. Disponível em: < http://www.planalto.gov.br/ccivil_03/leis/L8884.htm>. Acesso em 22/10/2018.

. Lei no 11.101, de 09 de Fevereiro de 2005. Disponível em: < http://www.planalto.gov.br/ccivil_03/_ato2004-2006/2005/lei//11101.htm>. Acesso em 22/10/2018.

. Lei 12.529, de 30 de Novembro de 2011. Disponível em: < http://www.planalto.gov.br/ccivil_03/_ato2011-2014/2011/Lei/L12529.htm>. Acesso em 22/10/2018.

. Guia para Análise Econômica de Atos de Concentração Horizontal. Publicado em 2016. Disponível em: < http://www.cade.gov.br/acesso-ainformacao/participacao-social-1/contribuicoes-da-sociedade/arquivos/guia-de-achorizontal.pdf $>$. Acesso em 22/10/2018.

COELHO, Fábio Ulhoa. Princípios do Direito Comercial. São Paulo: Saraiva, 2012.

COMPARATO, Fábio Konder. 0 indispensável direito econômico. Revista dos Tribunais, São Paulo, v.353, mar., pp. 14-26, 1965. 
Personalidade Acadêmica Homenageada:

Augustus B. Cochran III (Agnes Scott College)

CRAVO, Daniela Copetti. Aplicação da teoria da failing company defense nos atos de concentração decorrentes da recuperação judicial: atribuição do Cade ou competência exclusiva do juízo falimentar? Publicado em 2010. Disponível em $<$ http://www.lexeditora.com.br/doutrina_23129121_APLICACAO_DA_TEORIA_DA_F AILING_COMPANY_DEFENSE_NOS_ATOS_DE_CONCENTRACAO_DECORREN TES_DA_RECUPERACAO_JUDICIAL_ATRIBUICAOADO_CADE_OU_COMPETEN CIA_EXCLUSIVA_DO_JUIZZO_FALIMENTAR.aspx >. Acesso em 22/10/2018.

ESTADOS UNIDOS DA AMÉRICA. U. S. Supreme Court. International Shoe Co. v. FTC, 280 U. S. 291 (1930). Julgado em 06.01.1930. Disponível em: <http://supreme.justia.com/us/280/291/>. Acesso em 22/10/2018.

. U. S. Supreme Court. Citizen Publishing Co. v. United States - 394 U.S. 131 (1969). Julgado em 10.03.1969a. Disponível em: <http://supreme.justia.com/cases/federal/us/394/131/>. Acesso em 22/10/2018.

FEDERAL TRADE COMMISSION - FTC. Horizontal Mergers Guideline. Publicado em 1997. Disponível em:< https://www.ftc.gov/sites/default/files/attachments/mergerreview/hmg.pdf>. Acesso em 22/10/2018.

. Horizontal Mergers Guideline. Publicado em 2010. Disponível em:<http://ftc.gov/os/2010/08/100819hmg.pdf>. Acesso em 22/10/2018.

FERNANDES, Roberta Figueira. Failing firm defense: utopia, teoria ou tese aplicável na análise antitruste brasileira? Monografia premiada $3^{\circ}$ lugar VIII Prêmio SEAE. Publicada em 2013. Disponível em: $<$ http://www.esaf.fazenda.gov.br/assuntos/premios/premios-1/premios/viii-premioseae-de-monografias-edicao-2013/monografias-2013/3o-lugar-tema-1>. Acesso em 22/10/2018.

FORGIONI, Paula A. Os fundamentos do antitruste. 5 ed. São Paulo: Revista dos Tribunais, 2012.

FRAZÃO, Ana. Propriedade e empresa - função social e abuso de poder econômico. São Paulo: Quartier Latin, 2006.

GONÇALVES, Everton das Neves e STELZER, Joana. Principle of Social and Economic Efficiency (PSEE) at the Brazilians Law: the normative and judicial decision taking. In Sequencia: Estudos Jurídicos e Políticos, (S. I.), v. 35, n. 68, pp. 261-290, Jun. 2014. ISSN 2177-7055. Disponível em: https://periodicos.ufsc.br/index.php/sequencia/article/view/2177- 
Personalidade Acadêmica Homenageada:

Augustus B. Cochran III (Agnes Scott College)

7055.2013v35n68p261/26955. Acesso em: 22/10/2018. Doi: http://dx.doi.org/10.5007/2177-7055.2013v35n68p261

GRAU, Eros Roberto. A ordem econômica na Constituição de 1988. 14 ed. São Paulo: Malheiros, 2010.

MOTTA, Massimo. Competition policy: theory and practice. 12 ed. New York: Cambridge University Press, 2009.

OLIVEIRA, Felipe Guimarães de. A Failing Company Defense e o Direito Antitruste: o soerguimento de empresas insolventes por meio de ato de concentração econômica. João Pessoa: CONPEDI, 2014, p. 302-328. Disponível em: < http://publicadireito.com.br/artigos/?cod=2babf18a3e44fc9f $>$. Acesso em $24 \mathrm{de}$ maio de 2018.

OLIVEIRA JÚNIOR, Fernando Antônio Alves de. A empresa em crise e o direito da concorrência: a aplicação da teoria da Failing Firm no controle brasileiro de estruturas e seus reflexos no processo de recuperação judicial e de falência. 2014. 159 f. Dissertação (Mestrado em Direito)—Universidade de Brasília, Brasília, 2014. Disponível em: <http://repositorio.unb.br/handle/10482/16424>. Acesso em 22/10/2018.

POSNER, Richard A. Antitrust law. 2. ed. Chicago: The University of Chicago Press, 2001.

PROENÇA, José Marcelo Martins. Concentração Empresarial e o Direito da Concorrência. São Paulo: Saraiva, 2001.

SOUZA, Washington Peluso Albino de; CLARK, Giovani. Direito Econômico e a Ação Estatal na Pós Modernidade. São Paulo: LTR, 2011.

STUCKE, Maurice E. Reconsidering Antitrust's Goals. Publicado em 2012. Disponível em: http://bclawreview.org/files/2012/03/04_stucke1.pdf. Acesso em 22/10/2018. 